\title{
Использование логистической кривой для оценки стоимости компании на развивающемся рынке
}

\author{
Иванов И.Ф. ${ }^{50}$
}

Данная работа посвящена модели логистической кривой и одной из возможностей ее применения в корпоративных финансах. Логистическая кривая по своим характеристикам позволяет реалистично моделировать стадии роста потребительских рынков $в$ развивающихся странах. Вылеляются три фазы: формирование базы будущего роста, бурный рост и насыщение рынка с затухающими темпами роста. В результате на основе логистической кривой можно строить динамические прогнозы рынка сбыта различных товаров. Такой прогноз особенно полезен при оценке стоимости компании на развивающемся рынке, что проиллюстрировано в статье на примере компании ОАО «Лебедянский».

\section{Введение}

Оценка стоимости компании на развивающемся рынке является сложной задачей. Одна из причин этого заключается в сложности прогнозирования рынка сбыта компании, динамики его развития. В данной работе предлагается математический аппарат для частичного решения этой проблемы. Логистическая кривая представляется достаточно простым и в то же время реалистичным описанием динамики роста рынков в развивающихся странах. Предлагаемый подход позаимствован из математической биологии, где он применяется для описания изменения численности популяции при ограниченных ресурсах среды.

Статья организована следующим образом. В первой части рассматривается оригинальная биологическая задача и ее описание с помощью логистической кривой. Далее предложенный аппарат будет трансформирован на экономическую задачу прогнозирования динамики индивидуальных рынков в развивающихся странах. Третья часть представляет собой иллюстративный пример использования логистической кривой в рамках задачи по оценке стоимости компании ОАО «Лебедянский».

\section{1. Логистическая кривая в других науках}

В данном разделе будет рассмотрена исходная модель, для описания которой была предложена логистическая кривая. Это позволит увидеть возможность применения кривой в экономике и те предпосылки, которые лежат в основе прогнозирования на ее основе.

Своими корнями логистическая кривая уходит в математическую биологию. В основу данной науки легли идеи Чапмана [Chapman, 1928; 1931] о том, что рост однотипных популяций определяется двумя факторами: биотическим потенциалом и сопротивлением среды. Биотический потенциал - это потенциальная скорость размножения вида в данных условиях, которая осуществляется при отсутствии ограничений в пище, отсутствии вредных продуктов жизнедеятельности и т.д. Однако в реальности среда (точнее, фиксированное количество ресурсов) ограничивает возможности и скорость роста популяции, что и получило название «сопротивление среды».

Количественное описание данной идеи было предложено Фергельстом [Verhulst, 1838] и Перлем и Ридом [Pearl, Reed, 1920] в виде логистической кривой.

\footnotetext{
${ }^{50}$ Старший преподаватель, кафедра экономики и финансов фирмы ГУ-ВШЭ.

Выпуск \#1(5), 2008 () Электронный журнал Корпоративные Финансы, 2008
} 
$Q$ - число организмов;

$t$ - время;

$\frac{d Q}{d t}-$ скорость размножения;

$\delta$ - потенциальная скорость размножения.

Тогда $\frac{d Q}{d t}=\delta \cdot Q$.

Последнее равенство представляет собой геометрическое уравнение, описывающее потенциальные возможности роста. Для выражения идеи снижения скорости роста популяции за счет конкуренции за ограниченные ресурсы (сопротивления среды) предложена следующая поправка.

K - максимальный размер популящии при заданном размере ресурсов в среде; $\frac{K-Q}{K}-$ относительное число незанятых мест (свободных возможностей роста); $\frac{d Q}{d t}=\delta \cdot Q \cdot \frac{K-Q}{K}-$ логистическая кривая Фергельст-Перля.

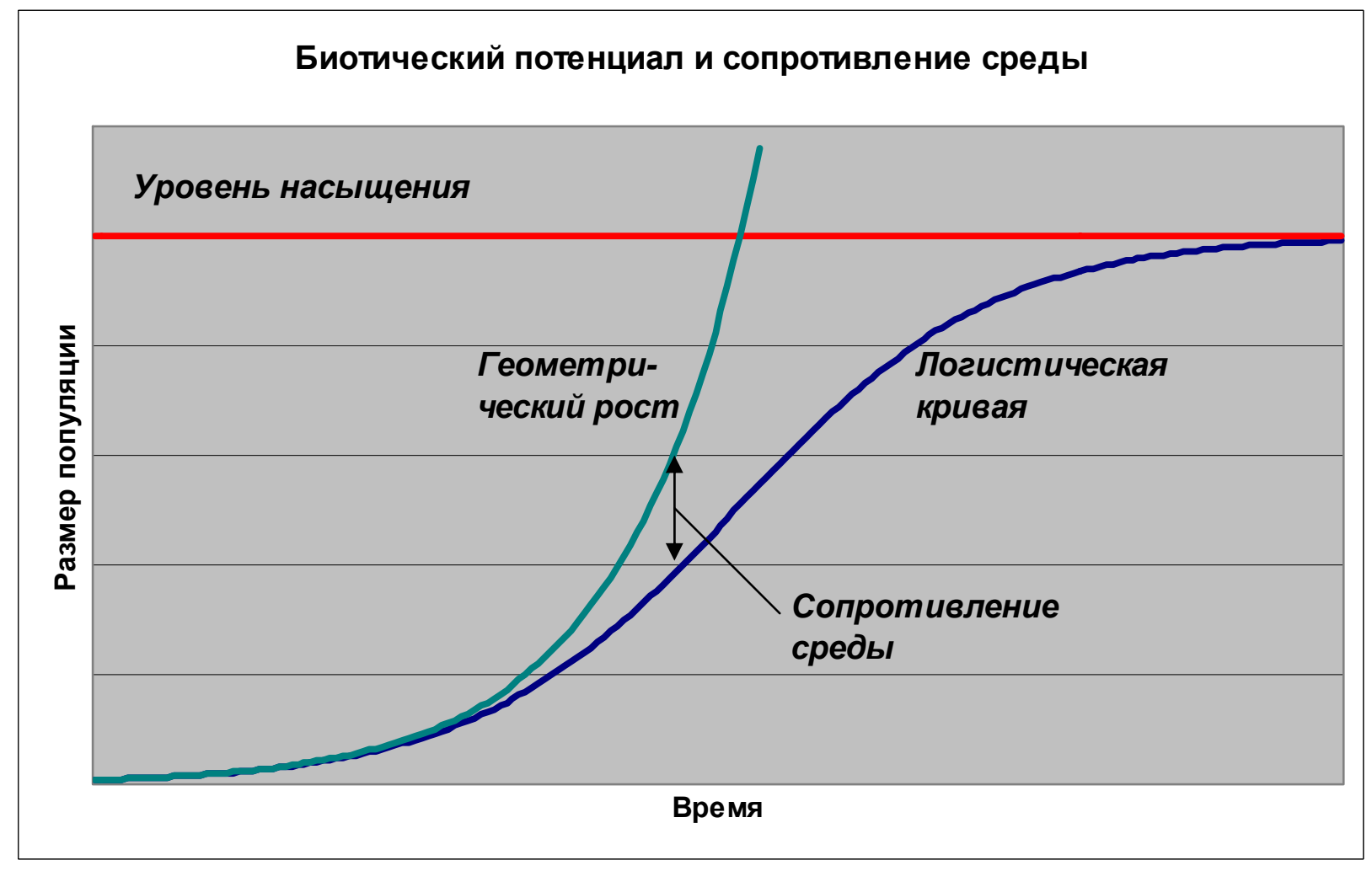

Рис.1

Будем измерять сопротивление среды как неосуществленную часть потенциального прироста. Интенсивностью борьбы за существование назовем сопротивление, которое нужно преодолеть для увеличения популяции на единицу. Тогда 


$$
\begin{aligned}
& 1-\frac{K-Q}{K}-\text { сопротивление среды; } \\
& \frac{\delta \cdot Q-\frac{d Q}{d t}}{\frac{d Q}{d t}}-\text { интенсивность борьбы за существование. }
\end{aligned}
$$

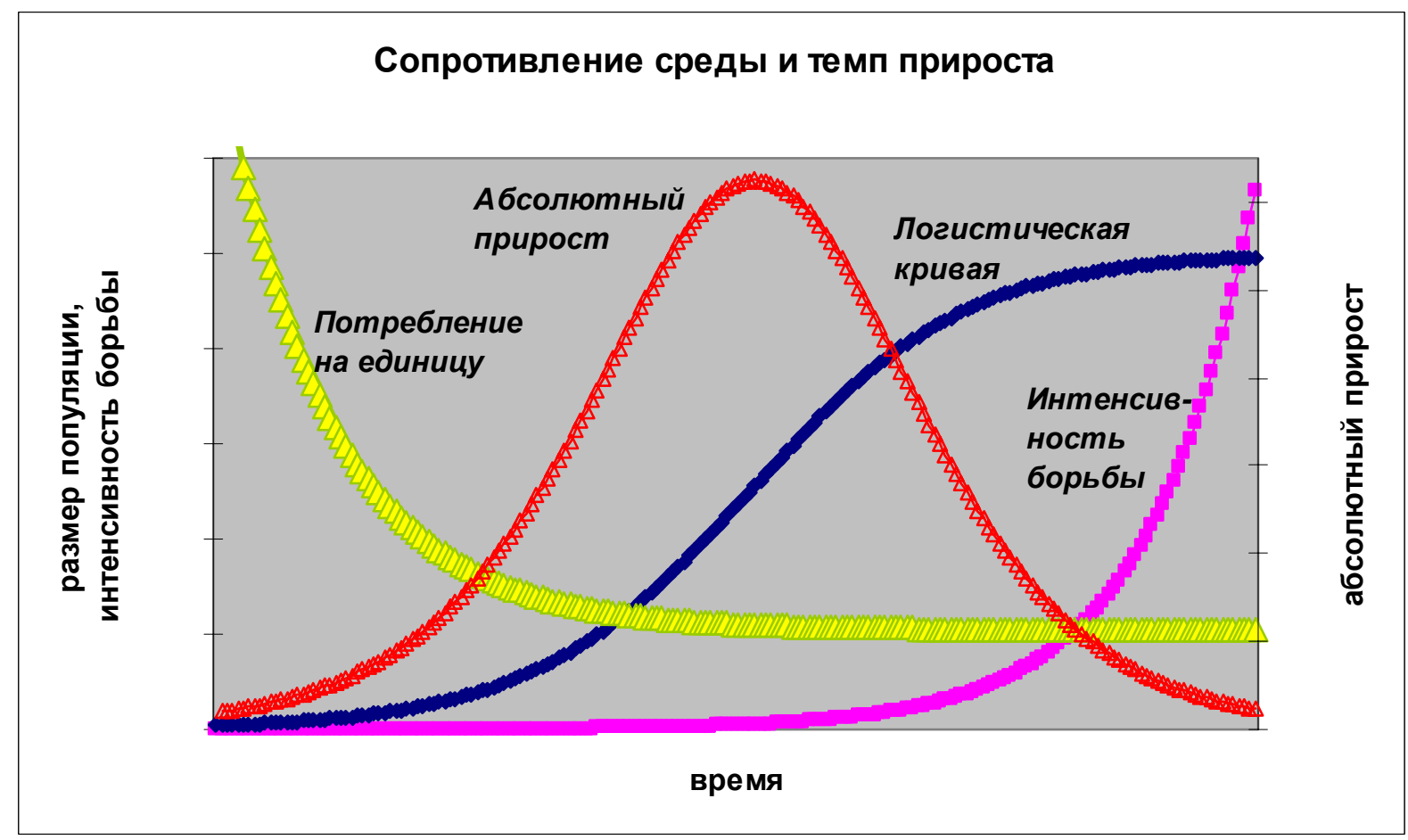

Рис. 2

Надеюсь, что у внимательного читателя уже возникло ощущение, что принципы действия биологической модели очень похожи на ситуацию, происходящую на развивающемся рынке. Преломлению данного аппарата к экономике и посвящен следующий раздел.

\section{2. Логистическая кривая в экономике}

Несмотря на известность, достаточную простоту и реалистичность, логистическая кривая практически не используется экономистами. Имеются лишь единичные работы, использующие ее, - например, работы Нижегородцева [1997] и Дятлова, Артамонова [1999]. В данной статье нас будет интересовать возможность описания с помощью логистической кривой динамики рынков в развивающихся странах.

Эта модель хорошо подходит для описания данного процесса в связи с тем, что закладываемые в нее «биологические» предпосылки характерны также и для экономической среды развивающихся стран:

- $\quad$ Текущее потребление большого спектра товаров и услуг ниже, чем в развитых странах, а значит, имеется большой потенциал роста.

- $\quad$ Каждый экономический агент может увеличивать свое текущее производство на некоторый постоянный процент.

- Происходит борьба конкурентов за ограниченный бюджет потребителя на данный вид товара, свободные рыночные ниши выявляются и осваиваются постепенно. В 
результате не весь потенциальный рост реализуется. Можно предполагать, что реальный рост (так же как и в биологической модели) осуществляется пропорционально относительной доступности свободных ниш на рынке.

- $\quad$ Получаемые с помощью модели три фазы развития рынка: формирование базы развития (медленный и постепенно возрастающий рост), бурный рост и насыщение (замедляющийся рост) - действительно характерны для большинства «простых» товарных рынков развивающихся стран.

Приведем в качестве примера историческую динамику объема двух потребительских рынков. ${ }^{51}$ Несложно заметить, что логистическая кривая действительно может описывать представленный на рис. 3 и 4 рост (в первом случае рынок стабилизировался, во втором завершается третья фаза).

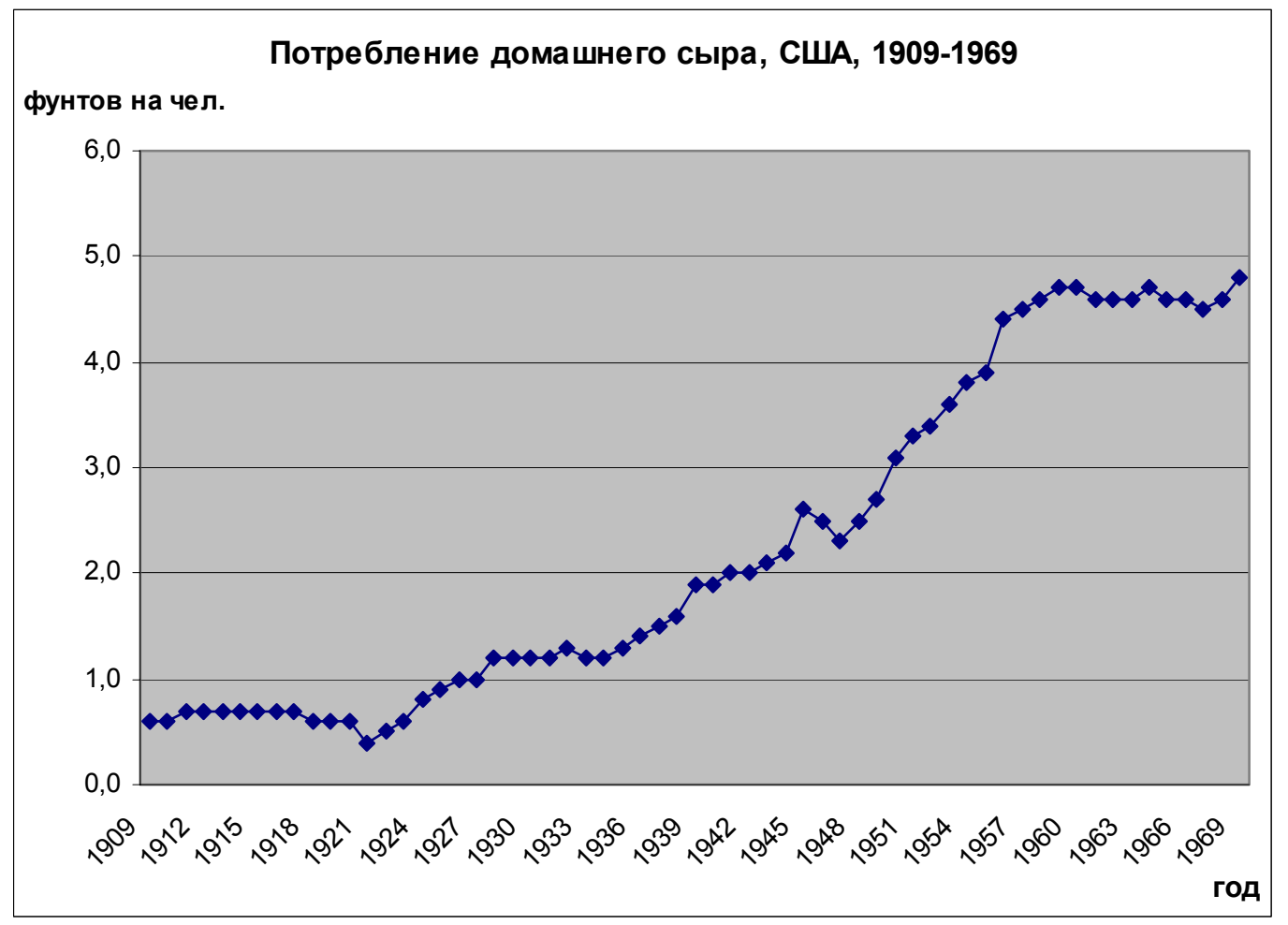

Рис. 3

\footnotetext{
${ }^{51}$ По данным USDA/Economic Research Service. 


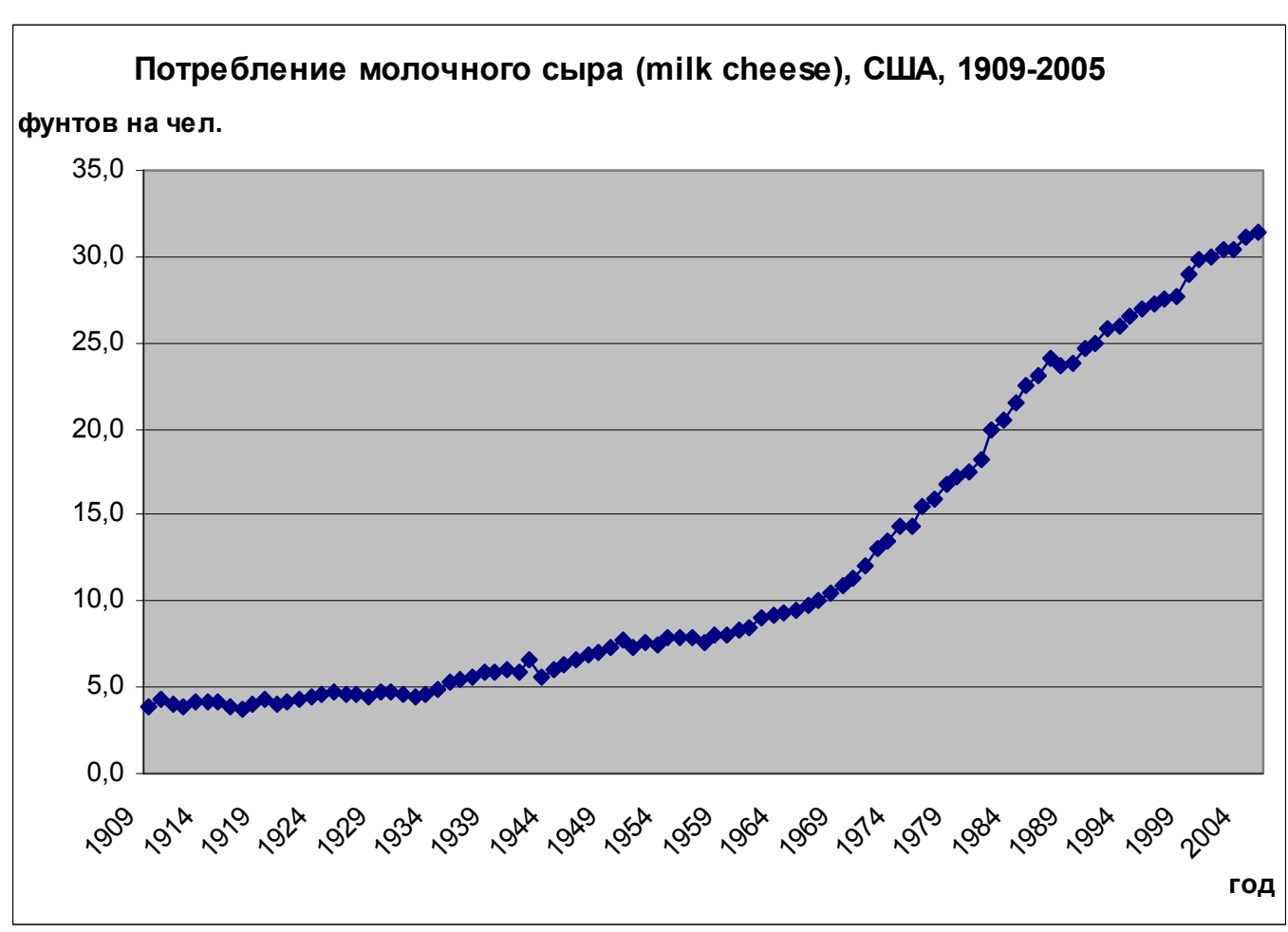

Рис. 4

В результате параметры нашей модели приобретут следующий экономический смысл:

$Q$ - объем рынка;

$t$ - время;

$\frac{d Q}{d t}$ - рост рынка в единицу времени;

$\delta$ - потенцииальный рост рынка.

Тогда $\frac{d Q}{d t}=\delta \cdot Q-$ геометрический рост.

K - потенцииальная (максимальная) емкость рынка;

$\frac{K-Q}{K}-$ относительная свободная ниша на рынке;

(свободные возможности роста)

$\frac{d Q}{d t}=\delta \cdot Q \cdot \frac{K-Q}{K}-$ логистическая кривая Фергельст-Перля.

$1-\frac{K-Q}{K}-$ конкурентное сопротивление;

$\frac{\delta \cdot Q-\frac{d Q}{d t}}{\frac{d Q}{d t}}-$ интенсивность конкурентной борьбы.

Отметим также, что с помощью кривой можно описывать долю отдельной компании на рынке. Такой аппарат можно применять для динамичных компаний, обгоняющих рынок. 
При этом компания должна проводить агрессивную маркетинговую кампанию или обладать компетентными преимуществами, например: сильным менеджментом; интеллектуальными разработками, защищенными патентом; производством нишевого товара, не представленного на рынке, и т.д.

С точки зрения корпоративных финансов ценность логистической кривой состоит не столько в описании динамики рынков, сколько в прогнозировании на основе кривой их будущего роста. Первый шаг — решим дифференциальное уравнение логистической кривой $^{52}$ :

$$
Q(t)=\frac{K}{1+c \cdot \exp (-\delta \cdot t)}
$$

Здесь существует два подхода по оценке неизвестных параметров. Во-первых, это эконометрический расчет коэффициентов по историческим данным. Здесь, к сожалению, существует ряд проблем. Необходимо обладать продвинутой техникой эконометрических расчетов, так как модель нелинейная. ${ }^{53}$ Более того, по развивающимся рынкам имеется незначительное число исторических данных, в основном сосредоточенных в первой фазе. В результате оценки параметров обладают низкой значимостью.

Альтернативным подходом можно считать формирование параметров на основе их экономического смысла, а именно:

$$
\begin{aligned}
& K-\text { потенциальная емкость рынка; } \\
& c=\frac{K-Q_{0}}{Q_{0}}-\text { относительный потенцииал роста в момент } t=0 \text {; } \\
& \delta \text {-средний темп роста в первые годы. }
\end{aligned}
$$

В качестве «потолка роста» можно предложить использовать показатели рынка соответствующего товара в развитых странах, сходных по культурным особенностям и пристрастиям в потреблении. Потребление товара на душу населения должно обладать в эталонных странах относительной стабильностью.

Таким образом, в данном разделе было показано, что модель логистической кривой из математической биологии может быть успешно применена для описания товарных рынков в развивающихся странах. В следующем разделе будет рассмотрена реальная задача по оценке стоимости компании ОАО «Лебедянский» с использованием предложенной выше методики прогнозирования.

\section{3. Оценка стоимости компании ОАО «Лебедянский»}

В данной части работы будет предложена реальная бизнес-задача по оценке стоимости собственного капитала компании ОАО «Лебедянский» с использованием предложенного выше подхода для прогнозирования динамики рынков сбыта компании. Оценка будет производиться на основе модели дисконтированного потока свободных денежных средств для акционеров на 1 января 2006 года.

Рассмотрим последовательно два основных блока построения оценки: прогнозирование денежных потоков и построение ставки дисконтирования (требуемой доходности на собственный капитал).

\section{1. Прогнозирование денежных потоков}

\footnotetext{
52 Здесь за $\mathrm{t}=0$ принята точка перегиба на графике, она же - точка максимального абсолютного прироста.

53 Данный недостаток легко преодолим с помощью специализированных эконометрических пакетов. В работах Каваллини [Cavallini, 1993] и Арнольд [Arnold, 2002] описываются методы расчетов для программ Mathematica и Matlab соответственно.
}

Выпуск \#1(5), 2008 
По состоянию на конец 2005 года компания занимается производством продукции трех направлений:

- Фруктовые и овощные соки (бренды «Я», «Тонус», «Фруктовый сад», «Frustyle»). Данное направление является для компании исторически первым и основным (доля выручки $^{54}$ - около 90\%, доля на рынке ${ }^{55}$ стабилизировалась на уровне 28-29\%). Валовая рентабельность производства соков ${ }^{5}$ на уровне $40 \%$. В условиях ужесточения конкуренции целью компании является сохранение текущих позиций на рынке.

- Детское питание (бренд «ФрутоНяня»). Это направление производства стало активно развиваться в последние годы с целью диверсификации бизнеса, смещения деятельности компании в более маржинальный сегмент. В 2005 году 10\% выручки было

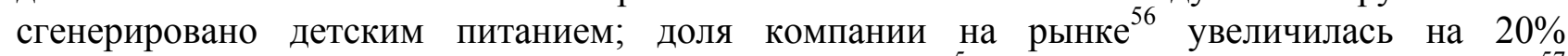
(относительно доли рынка в 2004 году). Рентабельность ${ }^{5}$ превысила 50\%. Целью компании ${ }^{57}$ является интенсивное развитие данного высокомаржинального направления, повышение его доли в выручке до $15 \%$ в ближайшие годы.

- Питьевая и минеральная вода (бренд «Липецкий бювет»). Данный сегмент рынка имеет многократный потенциал роста (при сравнении с развитыми странами), темп прироста потребления бутилированной воды в России за последние годы ${ }^{7}$ составил $20-30 \%$. В 2005 году доля на рынке компании ${ }^{7}$ была менее $1 \%$. Валовая рентабельность ${ }^{5}$ ниже, чем по другим направлениям ОАО «Лебедянский», около 30\%. Целью компании является дальнейшее развитие данного направления, однако вывод водного бренда «Липецкий бювет» на общенациональный рынок не планируется. Цель компании ${ }^{8}$ - в расширении его доли на рынке до $2 \%$.

В результате выручка компании формируется тремя основными денежными потоками. Они характеризуются

- различным вкладом в выручку;

- различными показателями валовой рентабельности;

- различной динамикой роста, так как:

о каждый сегмент рынка находится на определенном этапе жизненного цикла (различный потенциал роста до показателей развитых стран),

о в каждом сегменте компания обладает различными компетенциями и соответственно потенциалом роста,

о представления и цели менеджмента по дальнейшему развитию соответствующих брендов различаются.

Поэтому представляется целесообразным производить оценку выручки компании по трем направлениям раздельно. В конечном итоге это позволит построить более качественные прогнозы финансовых показателей. Рассмотрим на примере сокового направления схему построения прогнозных денежных потоков.

\subsection{1. Построение прогнозных денежных потоков по соковому направлению}

Для описания затухающего роста на рынке соков ${ }^{58}$ (по мере насыщения рынка и с началом борьбы за «сложных» региональных клиентов) предлагается использовать рассмотренный выше подход — на основе логистической кривой. С помощью логистической модели прогнозируется динамика продаж всей отрасли фруктовых и овощных соков в России (в дальнейшем данный метод используется также и для описания изменения доли

\footnotetext{
${ }^{54}$ По данным бухгалтерской отчетности компании.

55 По данным агентства AC Nielsen.

${ }^{56}$ По данным агентства Euromonitor International.

${ }^{57}$ Интервью исполнительного директора Магомета Тавзакова // «Прямые инвестиции», № 3 (59), 2007.

58 За период с 2000-го по 2005 год темпы прироста потребления соков на душу населения постепенно снижались с 37 до 10\% (по данным Euromonitor International).
}

Выпуск \#1(5), 2008 () Электронный журнал Корпоративные Финансы, 2008 
рынка детского питания и воды компании во времени). Также во всех примерах прогнозирование ведется на основе выбора значений параметров с учетом их экономического смысла.

В качестве потенциальной емкости российского рынка рассматривается средний показатель потребления сока на душу населения в европейских странах за 2000-2005 годы. ${ }^{7}$ При этом учитываются только страны, схожие с Россией по географической широте (Германия, Швеция, Великобритания и др.). Южные страны не рассматриваются из-за наличия в них большого изобилия фруктов, что нехарактерно для России и соответственно исказило бы потенциальную емкость. Показатель рассчитан на уровне 30 литров сока на душу населения в год, начальный период - 2003 год ${ }^{59}$, относительный потенциал роста ${ }^{60}$ 1,88 , темп роста в первые годы - 24\%. Смоделирована следующая динамика рынка овощных и фруктовых соков:

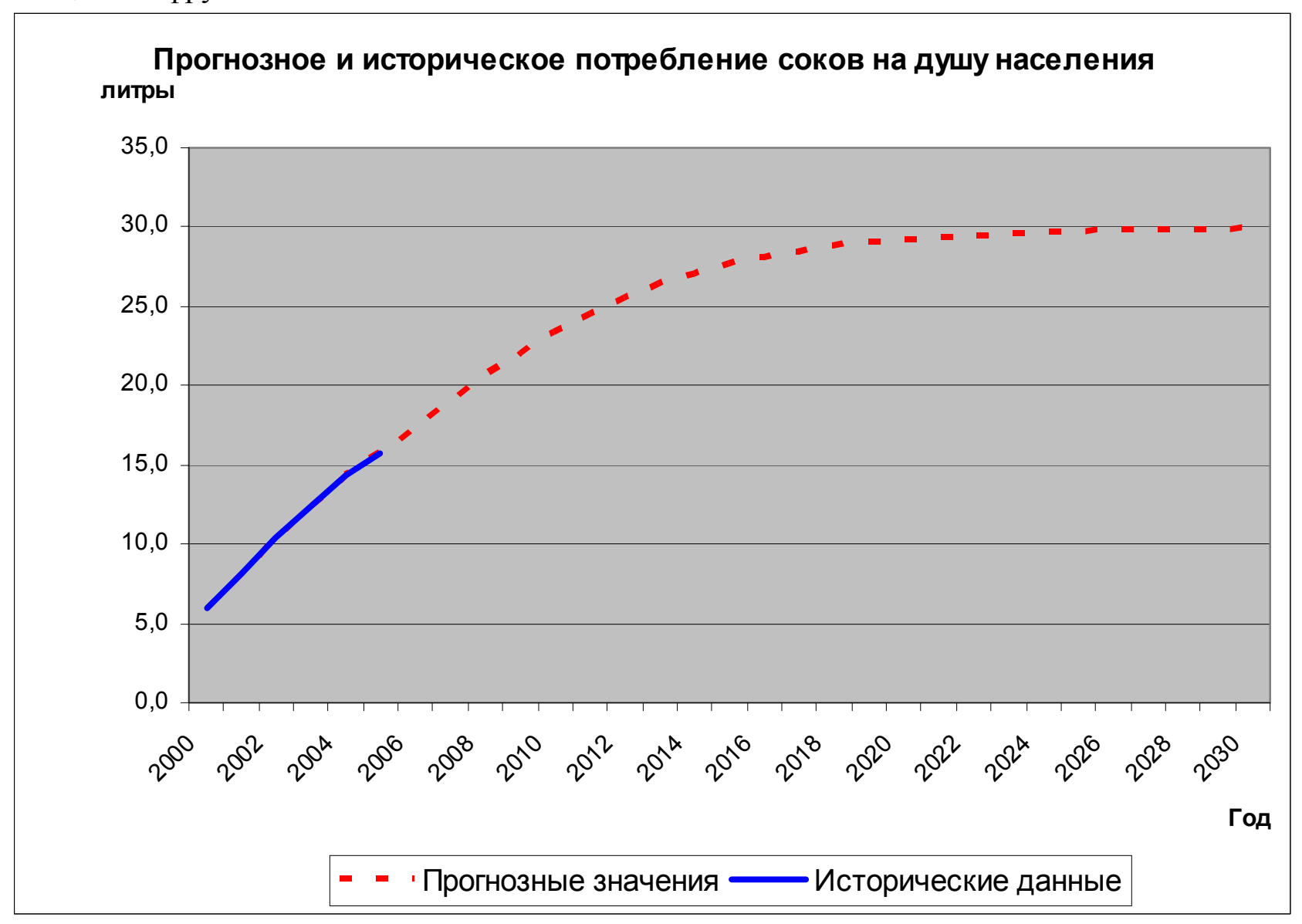

\section{Рис.5}

С учетом исторической динамики потребления соков прогноз выглядит достаточно реалистично (рис. 5). По заявлению руководства компании ${ }^{8}$, возможности дальнейшей экспансии на соковом рынке достаточно ограничены и основной целью компании является удержание текущей доли рынка. Данная цель представляется вполне реалистичной: с одной стороны, на рынке происходит ужесточение конкуренции; а с другой, компания обладает компетентным менеджментом, четко позиционированной и сегментированной продуктовой линейкой. В результате предполагается сохранение компанией доли рынка на уровне $30 \%$. Стоит учесть тот факт, что в планы ОАО «Лебедянский» входит строительство нового завода

\footnotetext{
59 Здесь рассматривается динамика рынка после 2003 года (то есть не рассматривается первая и вторая фазы логистической кривой).

${ }^{60}$ Потребление фруктовых и овощных соков на душу населения в России в 2005 году составило 12,4 литра (по данным Euromonitor International).
} 
в Сибирском регионе. В расчеты закладывается строительство завода мощностью 300 млн литров в год и стоимостью 44 млн долл. США ${ }^{61}$, что позволит сократить издержки на транспортировку продукции в восточные регионы и расширить свою долю (20\% в 2005 году ${ }^{62}$ в в восточной части страны. При сохранении текущей средней загрузки производственных мощностей ${ }^{5}(77 \%)$ это приведет к постепенному дополнительному расширению доли компании на 5\% (200 млн литров от потенциального объема рынка 4 млрд литров).

Все расчеты будут производиться в реальных величинах, то есть в ценах конца 2005 года. Предполагается, что в дальнейшем сохранится текущая реальная цена. С одной стороны, рост цен в соковой индустрии несколько ниже уровня инфляции. ${ }^{63} \mathrm{C}$ другой стороны, структура спроса (при повышении платежеспособности населения) постепенно сместится в сторону более дорогих брендов, о чем свидетельствует историческое изменение структуры потребления в западноевропейских странах. В итоге предполагается взаимное погашение этих эффектов, что приводит к неизменности реальной цены. В результате на основе учета динамики рынка, доли компании и удельной выручки на литр сока формируется прогноз выручки компании.

Валовая рентабельность сокового направления компании в последние несколько лет — около 40\%. Предполагается, что компания сможет сохранить показатель 2005 года еще в течение трех лет. Далее произойдет равномерное снижение рентабельности до $30 \%$, что соответствует средним показателям западноевропейских аналогов (Eckes-Granini GmbH Co KG (32\% в 2005 году), Cadbury Schweppes (30\% в 2005 году) и др.) и связано с ужесточением конкуренции по мере насыщения рынка. Аналогом данного падения прибыльности компании является снижение потребления ресурсов на единицу популяции в биологической модели на рис. 2 до некоторого минимально приемлемого уровня. В результате динамика выручки и валовой прибыли компании выглядит следующим образом (приводится лишь часть расчетной таблицы).

\begin{tabular}{|l|l|l|l|l|l|l|l|l|l|l|l|l|}
\hline \multicolumn{2}{|c|}{ Расчетная таблица для прогнозирования финансовых показателей компани поковому направлени } \\
\hline & $\mathbf{2 0 0 5}$ & $\mathbf{2 0 0 6}$ & $\mathbf{2 0 0 7}$ & $\mathbf{2 0 0 8}$ & $\mathbf{2 0 0 9}$ & $\mathbf{2 0 1 0}$ & $\mathbf{2 0 1 1}$ & $\mathbf{2 0 1 2}$ & $\mathbf{2 0 1 3}$ & $\mathbf{2 0 1 4}$ & $\mathbf{2 0 1 5}$ & $\mathbf{2 0 1 6}$ \\
\hline $\begin{array}{l}\text { Потребление соков на душу } \\
\text { населения, литр }\end{array}$ & 15,7 & 17,3 & 19,0 & 20,6 & 22,1 & 23,4 & 24,5 & 25,5 & 26,3 & 27,0 & 27,6 & 28,1 \\
\hline $\begin{array}{l}\text { Население России, млн чел. } \\
\text { Суммарное потребление } \\
\text { соков, млн литров }\end{array}$ & 143,47 & 142,75 & 142,05 & 141,39 & 140,76 & 140,18 & 139,64 & 139,14 & 138,68 & 138,26 & 137,86 & 137,49 \\
\hline Доля рынка компании, \% & $29 \%$ & $30 \%$ & $30 \%$ & $30 \%$ & $31 \%$ & $32 \%$ & $33 \%$ & $34 \%$ & $35 \%$ & $35 \%$ & $35 \%$ & $35 \%$ \\
\hline $\begin{array}{l}\text { Объем продаж компании, } \\
\text { млн литров }\end{array}$ & 643,6 & 742,5 & 811,0 & 874,6 & 963,1 & 1048,4 & 1129,4 & 1205,8 & 1277,4 & 1307,0 & 1331,0 & 1349,9 \\
\hline $\begin{array}{l}\text { Средняя цена реализации, } \\
\text { руб. }\end{array}$ & 18,5 & 18,5 & 18,5 & 18,5 & 18,5 & 18,5 & 18,5 & 18,5 & 18,5 & 18,5 & 18,5 & 18,5 \\
\hline $\begin{array}{l}\text { Объем продаж компании, } \\
\text { млн руб. }\end{array}$ & 12621 & 13764 & 15034 & 16212 & 17854 & 19435 & 20937 & 22352 & 23680 & 24230 & 24673 & 25024 \\
\hline Валовая рентабельность, \% & $44 \%$ & $44 \%$ & $44 \%$ & $44 \%$ & $43 \%$ & $42 \%$ & $41 \%$ & $40 \%$ & $39 \%$ & $38 \%$ & $37 \%$ & $36 \%$ \\
\hline Валовая прибыль, млн руб. & 5503 & 6001 & 6555 & 7069 & 7606 & 8085 & 8500 & 8851 & 9140 & 9110 & 9030 & 8909 \\
\hline
\end{tabular}

\footnotetext{
61 В соответствии с инвестиционными планами, озвученными в информационном меморандуме к облигационному займу от 02.2007 года.

${ }^{62}$ По данным агентства AC Nielsen.

${ }^{63}$ На основе индекса цен продаж компании, по данным бухгалтерской отчетности за 2005 год.

Выпуск \#1(5), 2008

(C) Электронный журнал Корпоративные Финансы, 2008
} 
Табл. 1

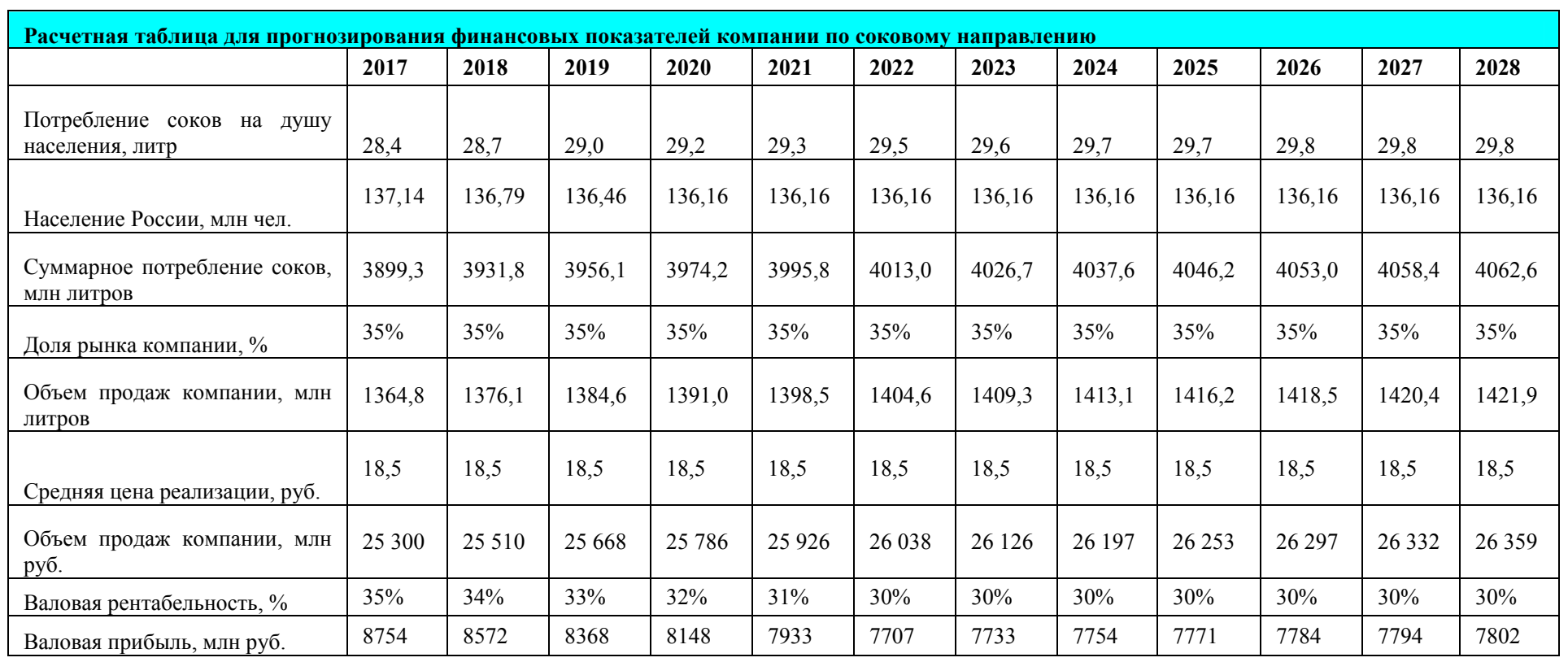

Табл. 2

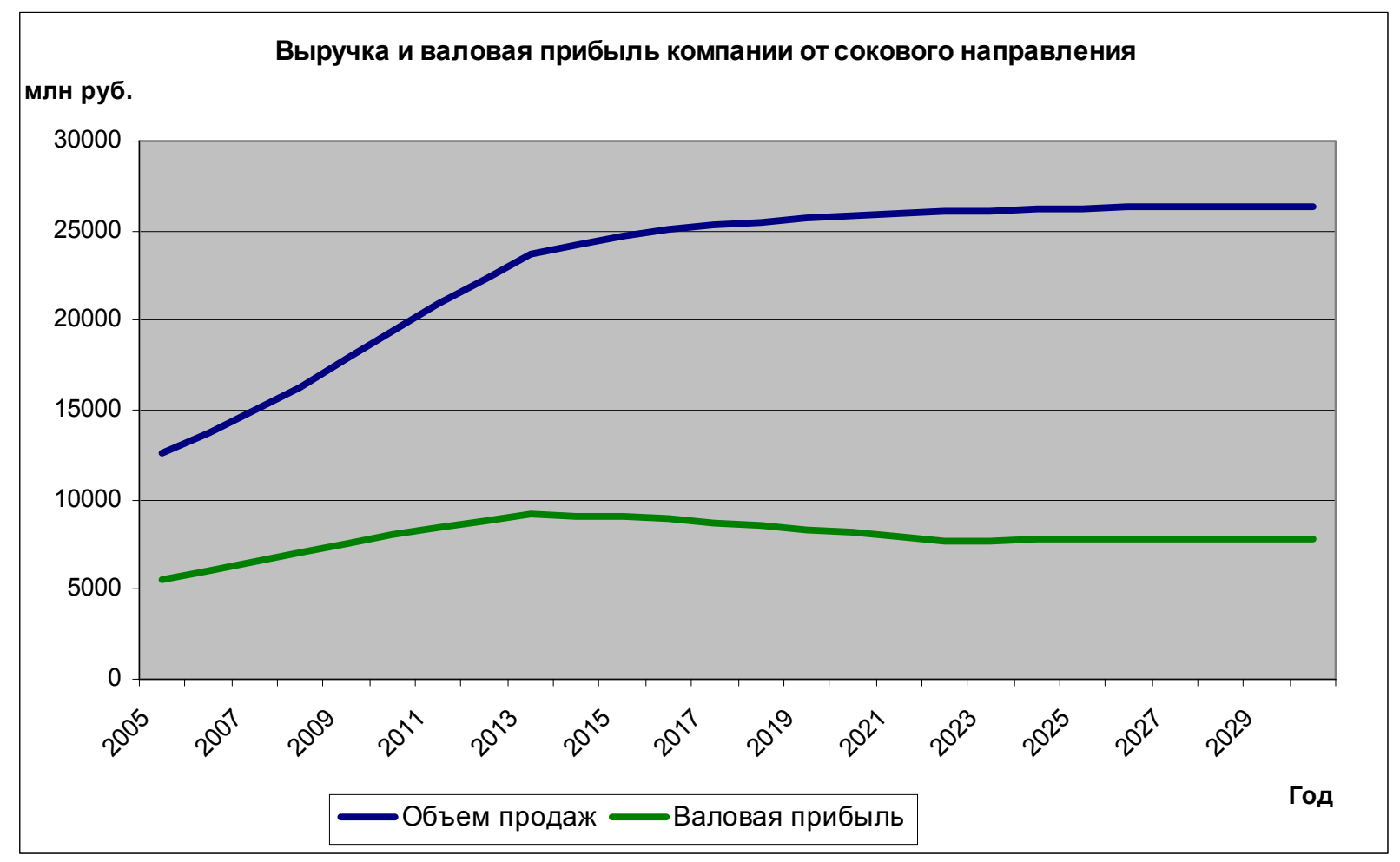

Рис. 6 


\subsection{2. Построение прогнозных денежных потоков по направлению детского питания и} бутилированной воды

Абсолютно аналогичный подход используется для оценки направлений детского питания и питьевой и минеральной воды. Отличия заключаются лишь в следующем:

- $\quad$ Потенциальная емкость российского рынка в двух сегментах рассчитывается как среднее потребление во всех западноевропейских странах за 2000-2005 годы («эффекта южных стран», как это было с соками, здесь не наблюдается).

- Ц Целью компании на этих рынка является удвоение ${ }^{8}$ собственной доли (до $10 \%$ на рынке детского питания и $2 \%$ на рынке бутилированной воды). Динамику подстройки к целевой доли рынка будем моделировать также с помощью логистической кривой. Это действительно правомерно, так как компания обладает компетентными преимуществами, однако по мере усиления конкуренции свободные ниши будут сужаться, рост доли замедлится и в дальнейшем стабилизируется.

- Валовая рентабельность детского питания находится на уровне 50\%. Как и в предыдущем направлении, через три года компания постепенно начнет терять рентабельность до $40 \%$. Валовая рентабельность питьевой и минеральной воды находится на уровне $30 \%$. Через три года показатель начнет снижаться до $20 \%$.

Что примечательно, логистическая кривая позволяет моделировать стадию жизненного цикла товара и интенсивность конкуренции. Так, если рынок соков находится уже на волне затухающего роста и высокой конкуренции (рис. 5), то рынок детского питания в средней точке излома (рис. 7), а рынок бутилированной воды - на стадии расширяющегося роста со слабой конкурентной борьбой (рис. 8).

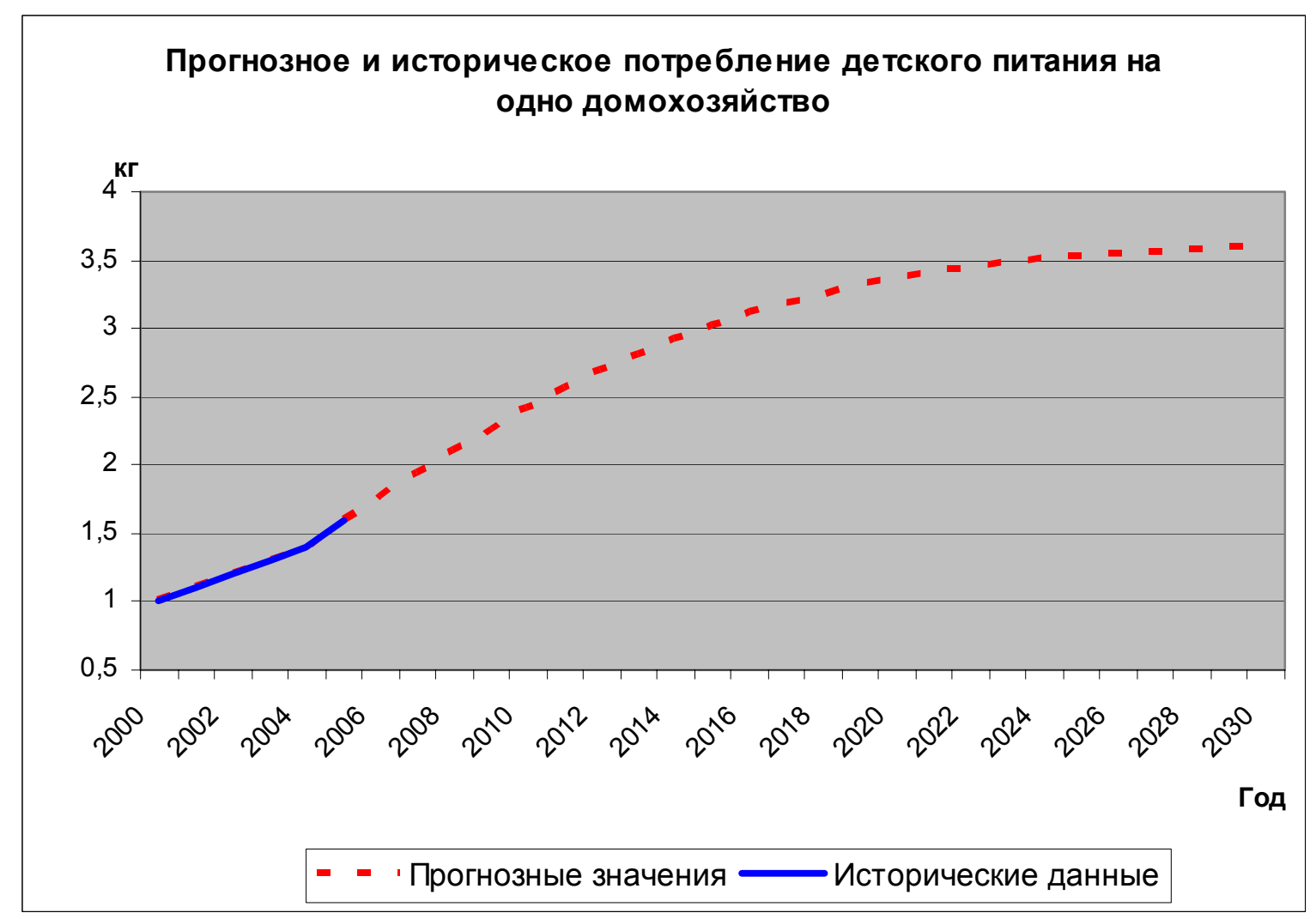

Рис. 7 


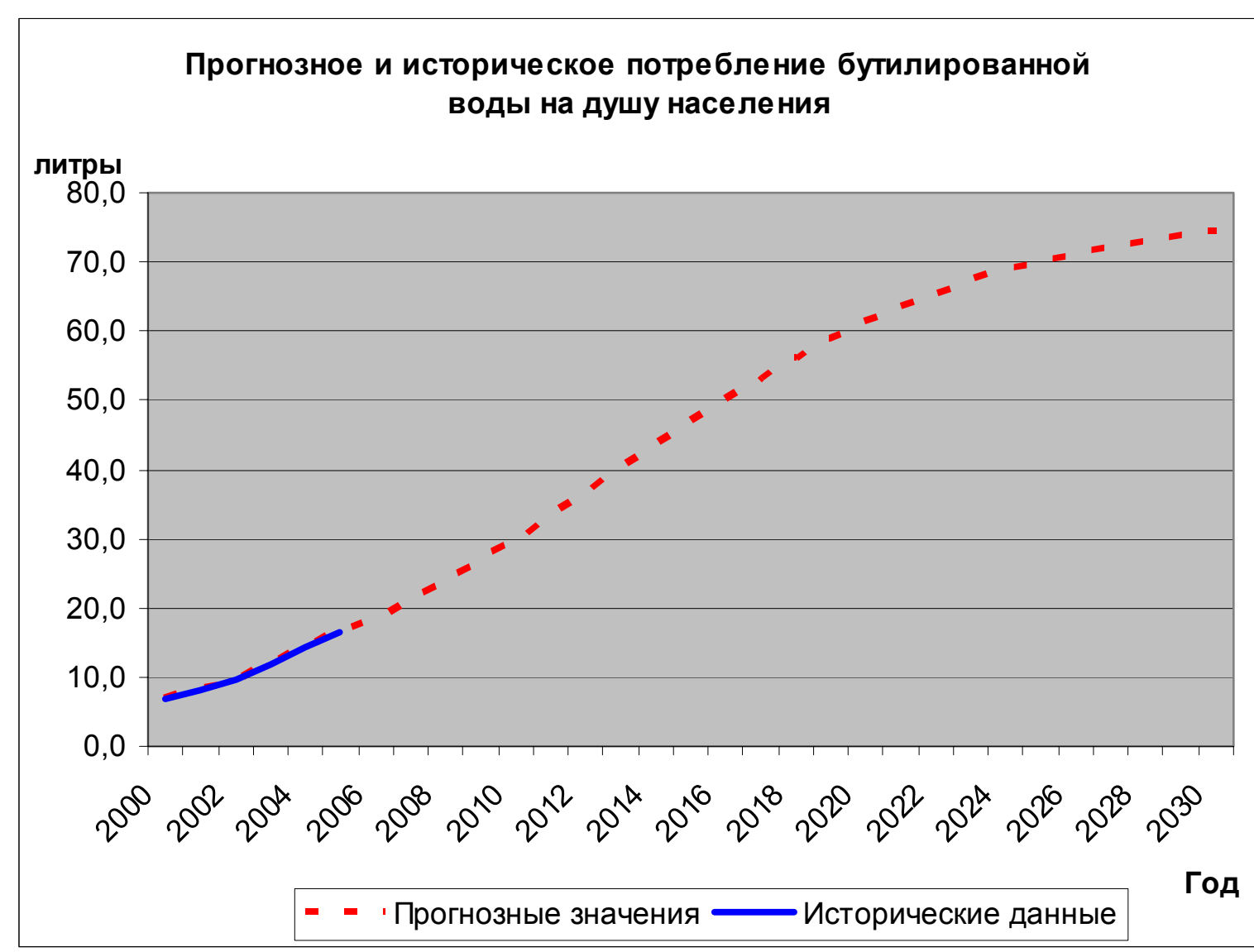

Рис. 8

\subsection{3. Расчет свободного потока денежных средств для акционеров}

Далее спрогнозированные потоки валовой прибыли агрегируются. Прогноз коммерческих, общих и административных расходов, а также прочих операционных расходов строится на основе средней исторической доли данных показателей в выручке.

Прогноз будущих платежей по обслуживанию долга строится на следующих предположениях:

- Компания сохранит текущие долгосрочные заимствования, но при этом будет увеличивать краткосрочные заимствования пропорционально выручке для финансирования текущих активов. процента.

- Рефинансирование долга будет осуществляться под действующие ставки

- Запланированное строительство завода в Сибирском регионе будет профинансировано за счет облигационного займа в размере 1500 млн рублей в 2007 году, который впоследствии будет также рефинансироваться.

Для оценки динамики амортизации можно предположить, что активы компании пропорциональны выручке, а значит, и амортизационные отчисления можно моделировать на основе средней исторической доли в выручке. Данный показатель в последние годы действительно был у компании достаточно стабилен. Также прирост чистого оборотного капитала соответствует приросту выручки с историческим коэффициентом 15\%. Планируемые инвестиционные вложения сформированы на основе планов компании. ${ }^{12}$ Далее приводится часть расчетной таблицы для получения денежного потока. 


\begin{tabular}{|c|c|c|c|c|c|c|c|c|c|c|}
\hline & 2006 & 2007 & 2008 & 2009 & 2010 & 2011 & 2012 & 2013 & 2014 & 2015 \\
\hline Выручка, в т.ч. & 15643 & 17335 & 18966 & 21079 & 23132 & 250962 & 26953 & 28691 & 29616 & 30396 \\
\hline соки & 13764 & 15034 & 16212 & 17854 & 19435 & 209372 & 22352 & 23680 & 24230 & 24673 \\
\hline детское питание & 1735 & 2116 & 2522 & 2940 & 3357 & 3760 & 4140 & 4490 & 4805 & 5085 \\
\hline вода & 143 & 184 & 232 & 284 & 340 & 400 & 461 & 521 & 581 & 638 \\
\hline Темп роста выручки & $11 \%$ & $11 \%$ & $9 \%$ & $11 \%$ & $10 \%$ & $8 \%$ & $7 \%$ & $6 \%$ & $3 \%$ & $3 \%$ \\
\hline Валовая прибыль, в т.ч. & 6964 & 7732 & 8475 & 9217 & 9892 & 10488 & 11000 & 11426 & 11508 & 11516 \\
\hline соки & 6001 & 6555 & 7069 & 7606 & 8085 & 8500 & 8851 & 9140 & 9110 & 9030 \\
\hline детское питание & 920 & 1122 & 1337 & 1529 & 1712 & 1880 & 2028 & 2155 & 2259 & 2339 \\
\hline вода & 43 & 55 & 69 & 82 & 95 & 108 & 120 & 130 & 139 & 147 \\
\hline Валовая рентабельность & $45 \%$ & $45 \%$ & $45 \%$ & $44 \%$ & $43 \%$ & $42 \%$ & $41 \%$ & $40 \%$ & $39 \%$ & $38 \%$ \\
\hline Коммерческие расходы & 2228 & 2469 & 2702 & 3003 & 3295 & 3575 & 3840 & 4087 & 4219 & 4330 \\
\hline Административные расходы & 824 & 913 & 999 & 1111 & 1219 & 1322 & 1420 & 1512 & 1560 & 1601 \\
\hline Прочие операционные расходы & 37 & 41 & 44 & 49 & 54 & 59 & 63 & 67 & 69 & 71 \\
\hline Операционная прибыль & 3875 & 4309 & 4729 & 5055 & 5324 & 5532 & 5677 & 5760 & 5660 & 5513 \\
\hline Расходы по выплате процентов & 44 & 141 & 142 & 143 & 144 & 145 & 146 & 146 & 147 & 147 \\
\hline Прибыль до налогообложения & 3831 & 4167 & 4587 & 4912 & 5180 & 5387 & 5531 & 5613 & 5513 & 5366 \\
\hline Чистая прибыль & 2911 & 3167 & 3486 & 3733 & 3937 & 4094 & 4204 & 4266 & 4190 & 4078 \\
\hline $\begin{array}{l}\text { Рентабельность } \\
\text { по чистой прибыли }\end{array}$ & $19 \%$ & $18 \%$ & $18 \%$ & $18 \%$ & $17 \%$ & $16 \%$ & $16 \%$ & $15 \%$ & $14 \%$ & $13 \%$ \\
\hline Амортизация & 330 & 365 & 400 & 444 & 487 & 529 & 568 & 605 & 624 & 640 \\
\hline Инвестиции & 1600 & 2650 & 2650 & 625 & 625 & 625 & 625 & 625 & 625 & 625 \\
\hline Изменение оборотного капитала & 242 & 254 & 245 & 317 & 308 & 295 & 278 & 261 & 139 & 117 \\
\hline \begin{tabular}{|ll} 
Чистое \\
долга
\end{tabular} & 0 & 1500 & 0 & 0 & 0 & 0 & 0 & 0 & 0 & 0 \\
\hline $\begin{array}{l}\text { Свободный денежный поток для } \\
\text { акционеров }\end{array}$ & 1399 & 2128 & 991 & 3235 & 3491 & 3703 & 3868 & 3985 & 4050 & 3977 \\
\hline
\end{tabular}

Табл. 3 


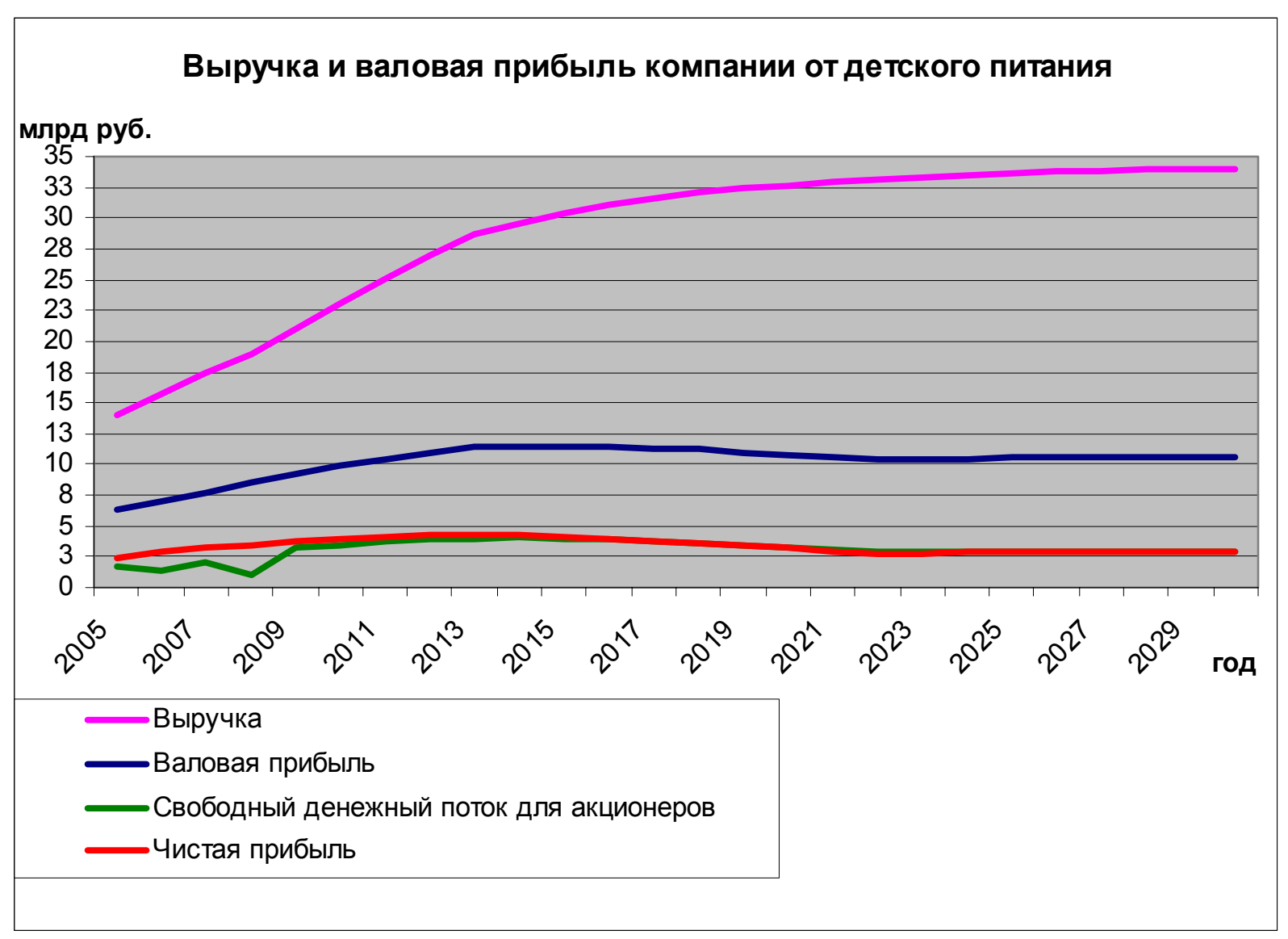

Рис. 9

Различия между денежным потоком и чистой прибылью в ближайшие годы связаны с активной инвестиционной политикой для укрепления производственной и дистрибьюторской базы, что необходимо для запланированного роста компании.

\section{2. Оценка ставки дисконтирования}

Ставка дисконтирования в данной модели рассчитывается как требуемая норма доходности на собственный капитал. Расчет будет производиться на основе гибридной модели САРМ с поправкой на страновой риск России. В качестве эталонной страны рассматриваются США.

$$
K_{\text {equity }}=\left[R_{\text {Tbond }}-\left(R_{\text {Tbond }}-R_{\text {Tbill }}\right)\right]-C P I+\beta \cdot\left(R_{\text {market }}-R_{\text {Tbill }}\right)+C R P_{\text {Russia }} \cdot
$$

Выбор модели связан с тем, что историческая динамика акций ОАО «Лебедянский» на конец 2005 года незначительна. Будут использованы среднеотраслевые значения показателя риска беты. ${ }^{64}$ На прогнозируемом периоде показатели компании демонстрируют как достаточно высокие темпы роста в ближайшие годы, так и близкие к нулю показатели в дальнейшем. Поэтому предлагается использовать различные ставки дисконтирования для периодов высокого (более 5\%) и низкого роста выручки. Это связано с различиями в рисках денежных потоков, генерируемых на растущем и стабильном рынках. Для построения двух различных ставок предлагается использовать беты (как характеристики риска компании) для развивающихся и развитых рынков соответственно. Первая из них будет использована для расчета доходности на периоде активного роста. По мере стабилизации рынка и

\footnotetext{
${ }^{64}$ На основе данных www.damodaran.com для отрасли beverage (soft drinks). 
соответственно выручки компании предполагается, что характеристика рискованности собственного капитала снизится до уровня компаний - аналогов развитых стран.

Безрисковая ставка процента оценивается как скорректированная краткосрочная ставка по усредненным месячным данным на историческом интервале 1976-2005 годы, соответствующем средней жизни инвестора в 30 лет. Показатель равен разнице между текущей доходностью 20-летних казначейских облигаций США и спредом за горизонт прогнозирования (на основе исторической разницы в доходности 20-летних казначейских облигаций и трехмесячных векселей). В дальнейшем безрисковая доходность корректируется на средний исторический показатель инфляции по индексу потребительских цен США для получения ставки дисконтирования реальных потоков.

Премия за рыночный риск в США считается как историческая разница месячных доходностей индекса S\&P500 и трехмесячных казначейских векселей США. Беты корректируются в соответствии с предполагаемым уровнем финансового рычага в размере $5,7 \%$, что рассчитано на основе предположений о динамике долга компании и капитализации компании на 31.12.2005 года. Премия за рыночный риск ${ }^{65}$ при текущем суверенном рейтинге России составляет $1,8 \%$. В результате получены следующие ставки дисконтирования для периодов высокого и низкого роста: 6,45 и 5,3\%.

Табл. 4

\begin{tabular}{|l|l|}
\hline \multicolumn{2}{|l|}{ Коррекция показателя бета } \\
\hline $\begin{array}{l}\text { Величина собственного капитала на } \\
\text { 31.12.2005, млрд руб. }\end{array}$ & 37,01 \\
\hline $\begin{array}{l}\text { Величина целевого долгосрочного } \\
\text { долгового финансирования, млрд руб. }\end{array}$ & 2,10 \\
\hline Финансовый рычаг & $5,68 \%$ \\
\hline Бета для периода высокого роста & 0,90 \\
\hline Бета для периода низкого роста & 0,58 \\
\hline
\end{tabular}

Табл. 5

\begin{tabular}{|l|l|}
\hline \multicolumn{2}{|l|}{ Расчет ставки дисконтирования } \\
\hline Безрисковая доходность в США & $5,00 \%$ \\
\hline Средняя инфляция в США & $3,60 \%$ \\
\hline Премия за рыночный риск в США & $3,59 \%$ \\
\hline Бета для периода высокого роста & 0,90 \\
\hline Бета для периода низкого роста & 0,58 \\
\hline Премия за страновой риск России & $1,80 \%$ \\
\hline $\begin{array}{l}\text { Требуемая норма доходности } \\
\text { периода высокого роста }\end{array}$ & $6,45 \%$ \\
\hline $\begin{array}{l}\text { Требуемая норма доходности } \\
\text { периода низкого роста }\end{array}$ & $5,30 \%$ \\
\hline
\end{tabular}

В результате оценка стоимости собственного капитала компании на основе модели дисконтированного потока свободных денежных средств для акционеров составила 52,2 млрд руб.

\section{Заключение}

В данной работе был рассмотрен простой математический аппарат, позволяющий моделировать динамику товарных рынков в развивающихся странах. Основной особенностью логистической модели является постановка темпа роста рынка в зависимость

\footnotetext{
${ }^{65}$ На основе данных www.damodaran.com.
}

Выпуск \#1(5), 2008 (С) Электронный журнал Корпоративные Финансы, 2008 
от относительного количества свободных ниш для развития. Данная предпосылка представляется достаточно реалистичной в связи с действиями конкурентов и сложностями поиска и заполнения свободных ниш на рынке. В результате кривая описывает три фазы развития товарного рынка: формирование базы развития (медленный и постепенно возрастающий рост), бурный рост и насыщение (замедляющийся рост). Одной из многих областей применения данного подхода является оценка стоимости компании на развивающемся рынке, что и было продемонстрировано в работе на примере ОАО «Лебедянский».

\section{Список литературы}

1. Дятлов А.Н., Артамонов С.Ю. Оптимизация маркетингового бюджета фирмы с использованием моделей S-образных кривых функций спроса // Экономический журнал Высшей школы экономики, № 4, 1999.

2. Нижегородцев Р.М. Модели логистической динамики как инструмент экономического анализа и прогнозирования // Сборник научных трудов экономического факультета Алтайского Государственного факультета «Моделирование экономической динамики: риск, оптимизация, прогнозирование», 1997. http://lise.asu.ru/lib/pub

3. Arnold D. Fitting a Logistic Curve to Data // College of the Redwoods, working material, 2002. http://online.redwoods.cc.ca.us/instruct/darnold

4. Cavallini F. Fitting a Logistic Curve to Data // The College Mathematics Journal, 24 (3), 1993. Pp. 247-253.

5. Chapman R. N. The quantitative analysis of environmental factors // Ecology 9, 1928. Pp. $111-122$.

6. Chapman R. N. Animal ecology. McGraw-Hill, New York, 1931.

7. Pearl R., Reed L.J. On the rate of growth of the population of the United States since 1790 and its mathematical representation // Proceedings of the National Academy of Science USA 6, 1920. Pp. 275-288.

8. Verhulst P.F. Notice sur la loi que la population suit dans son accroissement // Correspondance Mathématique et Physique publiée par A. Quetelet, 10, 1838. Pp.113-121. 